\title{
EFFECTS OF A STRONG MAGNETIC FIELD ON BOILING OF POTASSIUM
}
A. P. Fraas
D. B. Lloyd
R. E. MacPherson 


\section{DISCLAIMER}

This report was prepared as an account of work sponsored by an agency of the United States Government. Neither the United States Government nor any agency Thereof, nor any of their employees, makes any warranty, express or implied, or assumes any legal liability or responsibility for the accuracy, completeness, or usefulness of any information, apparatus, product, or process disclosed, or represents that its use would not infringe privately owned rights. Reference herein to any specific commercial product, process, or service by trade name, trademark, manufacturer, or otherwise does not necessarily constitute or imply its endorsement, recommendation, or favoring by the United States Government or any agency thereof. The views and opinions of authors expressed herein do not necessarily state or reflect those of the United States Government or any agency thereof. 


\section{DISCLAIMER}

Portions of this document may be illegible in electronic image products. Images are produced from the best available original document. 
This report was prepared as an account of work sponsored by the United States Government. Neither the United States nor the United States Atomic Energy Commission, nor any of their employees, nor any of their contractors, subcontractors, or their employees, makes any warranty, express or implied, or assumes any legal liability or responsibility for the accuracy, completeness or usefulness of any information, apparatus, product or process disclosed, or represents that its use would not infringe privately owned rights. 
Contract No. W-7405-eng-26

Reactor Division

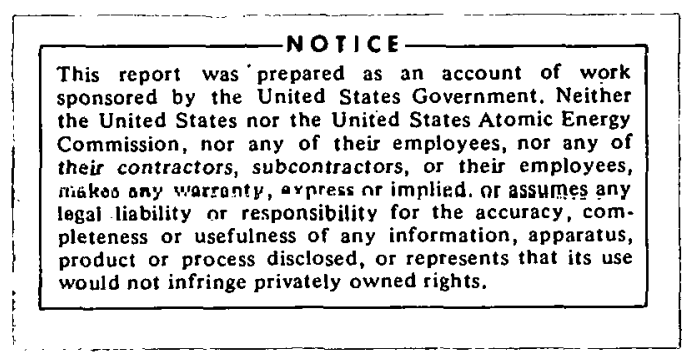

EFFECTS OF A STRONG MAGNETIC FIEID ON BOILING OF POTASSIUM
A. P. Fraas
D. B. Lloyd

R. E. MacPherson

FEBRUARY 1974

\begin{abstract}
NOTICE This document contains information of a preliminary nature and was prepared primarily for internal use at the Oak Ridge National Laboratory. It is subject to revision or correction and therefore does not represent a final report.
\end{abstract}

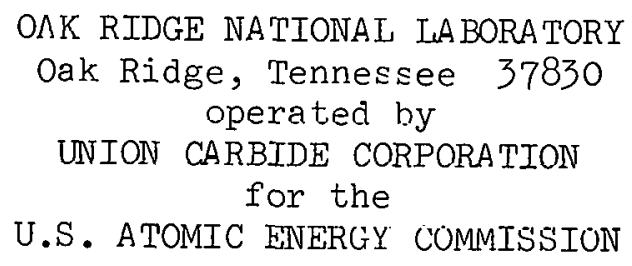


THIS PAGE

WAS INTENTIONALLY

LEFT BLANK 
CONTENTS

Page

ABSTRACT . . . . . . . . . . . . . . . . . . 1

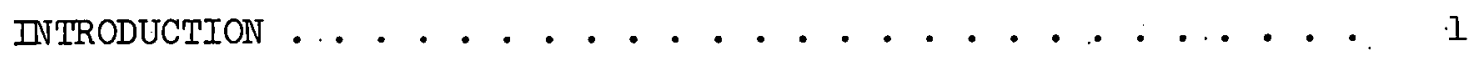

ANALYSIS . . . . . . . . . . . . . . . . . 2

Boiling Flow Regimes . . . . . . . . . . . . . 2

Bubble Growth .................... 5

Vclooity of Buhhle Djlation .............. . . 7

MHD Effects on Nucleation . . . . . . . . . . . 9

MHD Effects on Boiling Sounds . . . . . . . .... . Il

APPARATUS . . . . . . . . . . . . . . . . . . . 12

Instrumentation .............. 12

TEST PROCEDURE . . . . . . . . . . . . . . . . 14

TEST RESULTS . . . . . . . . . . . . . ..... 15

Spread in Boiler Temperatures . . . . . . . . 18

Effects of Magnetic Field ............... 18

Sanborn Recorder Charts ... ............ . 22

Termination of the Test . . . . . . . . . 27

CONCLUSIONS . . . . . . . . . . . . . . . . . . 27

REFEREINCES . . . . . . . . . . . . . . . . . . . 28 
EFFECTS OF A STRONG MAGNETIC FIELD ON BOILING OF POTASSIUM

A. P. Fraas, D. B. Lloyd, and R..E. MacPherson

ABSTRACT

One of the most promising ways to cool the lithium blanket of a full-scale fusion reactor is to employ a once-through potassium boiler in the blanket. A question has been raised as to whether this approach might have the disadvantage that magnetohydrodynamic effects might inhibit nucleate boiling. An analysis of the problem indicates that this is not the case, and an experiment has been run in which potassium has been boiled in magnetic fi.elds ranging from 0 to $50,000 \mathrm{G}$. This work indicates that the presence of a strong magnetic field will have small ef'tects on nucleate boiling of potassium, but there should be no serious effects so far as the operation of the boiler is concerned. The principal effects noted in the course of the experiment were some small changes in the boiling sounds and some small changes in the boiler temperature distribution. The change in sound is believed to result from an inhibiting effect of magnetohydrodynamic forces on the rate of implosion of bubbles, and the change in temperature distribution is believed to have stemmed from small changes in the thermal convection flow pattern in the boiler so that there was a small change in the distribution of energy input between nucleation sites in going from a zero magnetic field to a strong magnetic field.

\section{TIVTRODUCTION}

Conceptual design studies carried out on full-scale thermonuclear power plants strongly favor the use of a lithium blanket at a temperature of around $1000^{\circ} \mathrm{C}^{1}{ }^{2}$ An especially promising way of removing heat from the hot lithium blanket entails the use of a set of once-through boiler tubes installed in the lithium blanket. ${ }^{1}, 3$ Liquid potassium would be supplied to these tubes and the vapor would be removed via a set of potassium vapor manifolds. The large heat of vaporization of the potassium makes it necessary to employ only a small flow of liquid potassium through the magnetic field into the boiler mounted in the blanket, thus reducing the pumping power required to forcc the liquid metal radially inward through the magnetic field 
by a factor of 30 as compared to operation with a non-boiling liquid metal coolant. By removing only potassium vapor, there is no magnetohydrodynamic pumping power loss involved in the exit flow.

Questions have been raised as to the possibility that magnetohydrodynamic forces might inhibit nucleate boiling in a system of this type. This report presents a simple analysis of the problems involved coupled with the results of an experiment conducted with a small potassium boiler mounted in a solenoid magnet which permitted operation with fields up to $50,000 \mathrm{G}$.

\section{ANALYSIS}

For purposes of this study the full-scale fusion reactor design presented in Ref. I was taken as the point of departure. Magnetohydrodynamic effects on the lithium flow and the temperature distribution in the blanket are treated in Refs. 3 and 4 for the basic design of Ref. 1. The detailed design of the once-through boiler was taken from Ref. 5. The arrangement envisioned is shown in Fig. 1. The potassium boiler tubes are arranged in panels with individual tubes shaped like hairpins with their axes essentially parallel to the lines of magnetic force of the toroidal field. Liquid potassium enters at one end, is heated to the boiling point, passes over a set of nucleation sites where nucleate boiling begins, and then boiling continues to dryness throughout the balance of the tube. There is little or no superheating of the vapor leaving the tube because the heat. transfer coefficient for the dry vapor is poor.

\section{Boiling Flow Regimes}

The character of the boiling changes as the potassium traverses the lenglh of the tube. As indicated in Fig. 2, after the liquid has traversed enough of the tube so that it is slightly superheated, nucleate boiling begins with bubbles being initiated from nucleation sites in the wall. The bubble density vuilds up rapidly with the bubbles growing in size and number until they represent over $50 \%$ by volume of the bubbly flow. The liquid wets the wall very tenaciously so that surface tension forces tend to keep the bulk of the liquid against the wall. Thus the bubbles tend to accumulate 


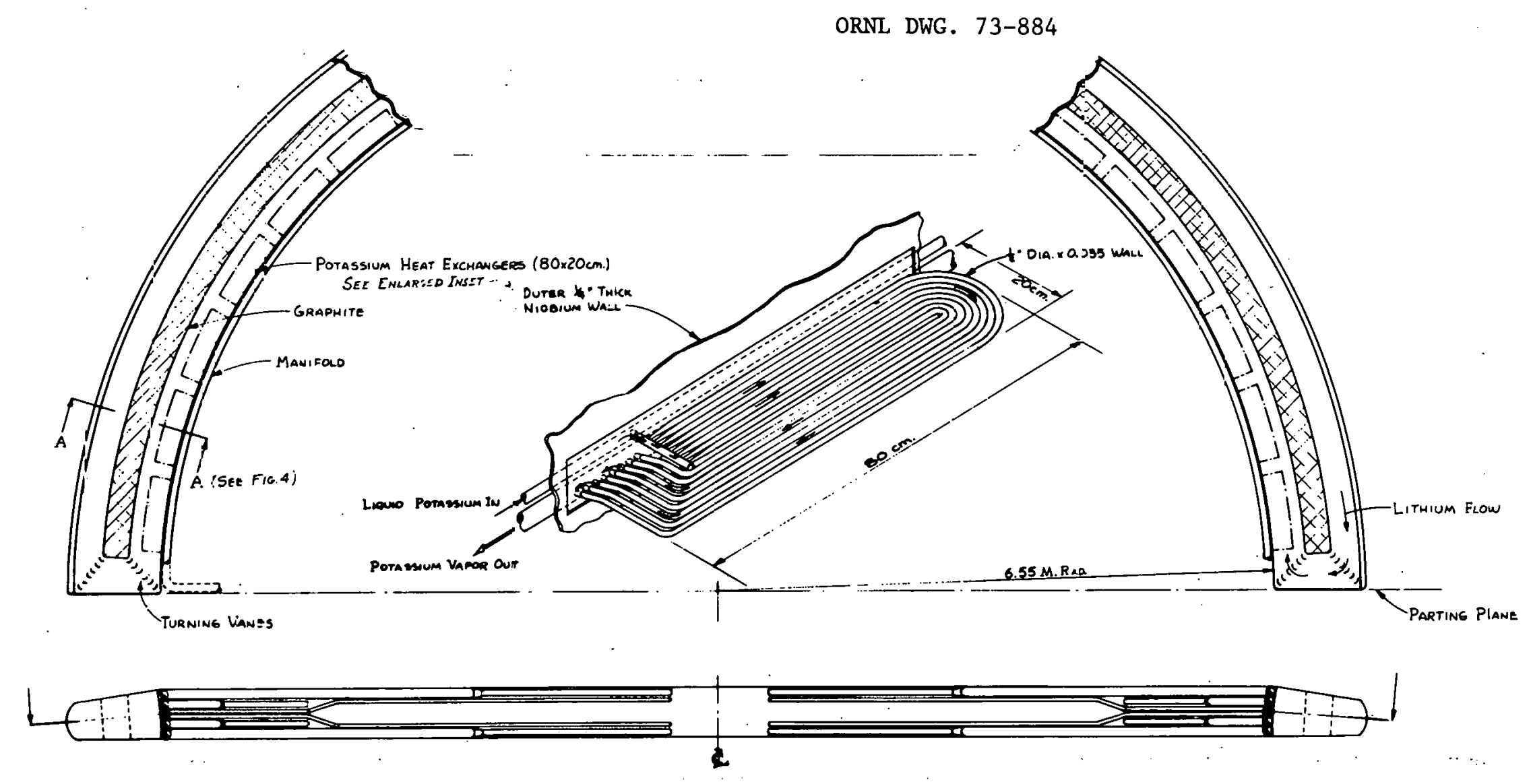

Fig. 1. Arrangement of once-through potassium boiler tubes in a typical blanket segment of the tokamak design of Ref. 1 . 


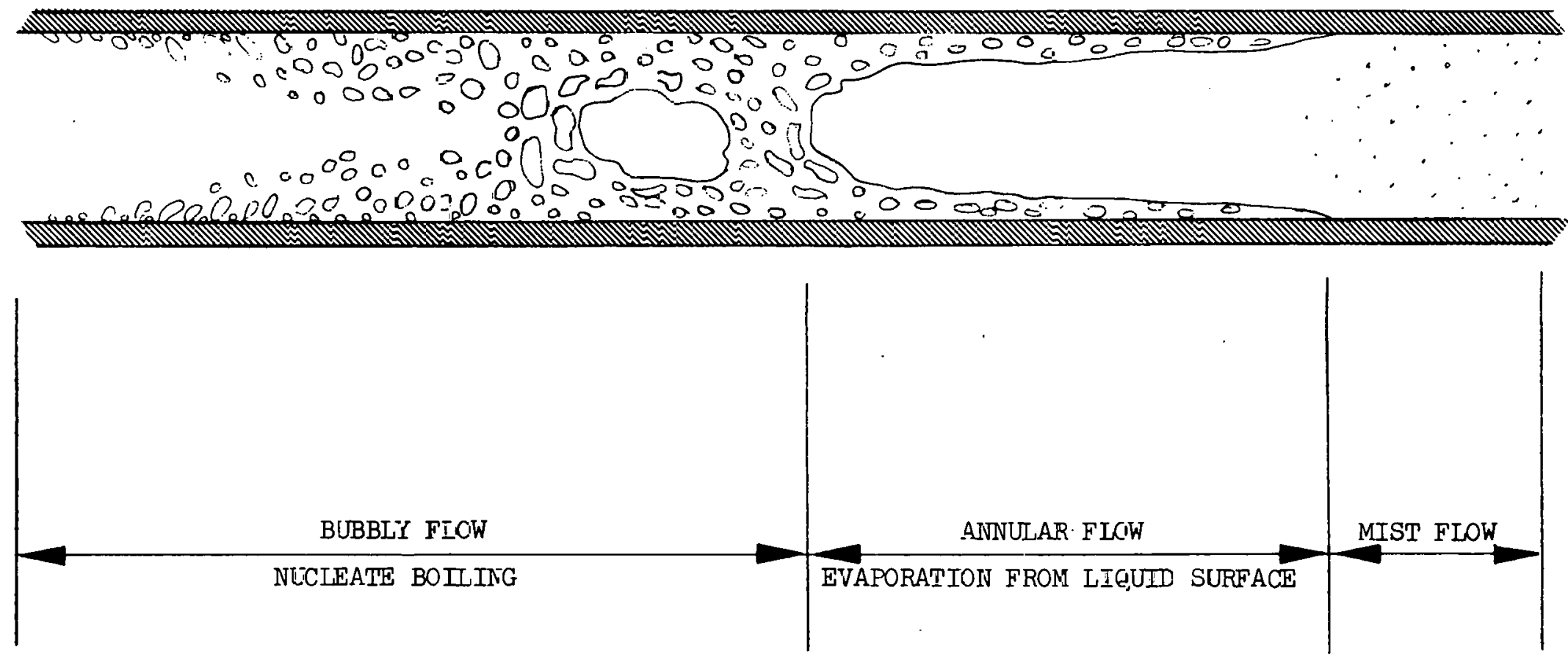

Fig. 2. Development of flow regimes in a once-through boiler tube. 
in the center and form a hollow core so that the flow regime shifts abruptly from the bubbly flow regime to an annular flow regime. This occurs quickly for the design conditions envisioned, i.e., within a few centimeters of the point where boiling begins. Once the potassium is in the annular flow regime evaporation takes place from the surface of the annular liquid film because the thermal conductivity of the potassium is so high that there is not sufficient temperature drop through the film to give the degree of superheat at the surface required to initiate bubbles at microscopic nucleation sites.

\section{Bulible Growth}

The flow regime in which magnetohydrodynamic forces appear to be most likely to be important is the nucleate boiling bubble flow regime near the inlet to the boiler tubc. In attempting to assess the problem, it appeared that the crucial question was the possible inhibiting effect of magnetohydrodynamic forces on bubble growth at a nucleation site. Typical steps in the formation of a bubble are indicated.in Fig. 3. The bubble begins at a microscopic nucleation site with the vapor expanding against the surface tension forces of what tends to be a large radius liquid-gas interface covering the nucleation site. As the bubble grows into a hemispherical cavity over the nucleation site, the radius of the curvature of the bubble rapidly decreases until. it equals the radius of curvature of the cavity that acts as the nucleation site. As this occurs the temperature of the vapor in the bubble must rise so that the difference between the vapor pressure. in the bubble and the local static pressure in the liquid will increase sufficiently to overcome the progressively more important surface tension forces as the radius of curvature of the free liquid surface is reduced. As the bubble gets still larger, its diameter begins to exceed that of the nucleation site and growth proceeds rapialy becauee eurface tension forces become progressively less important, the pressure in the bubble drops as expansion proceeds, and vapor is emitted from the superheated liquid surrounding the free surface so that the surrounding liquid is cooled down to the average temperature of the bulk free liquid stream. 6

As the bubble grows, both buoyancy and drag forces acting on the bubble tend to draw.it away from the nucleation site and this leads to a necking- 
ORNL DWG. 74-1228

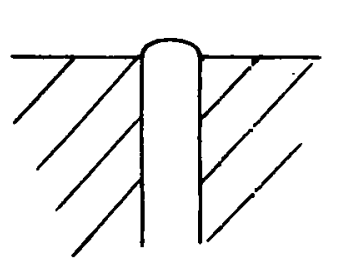

(a)

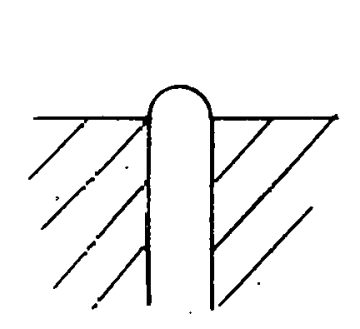

(b)

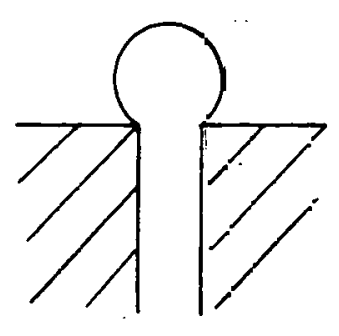

(ci

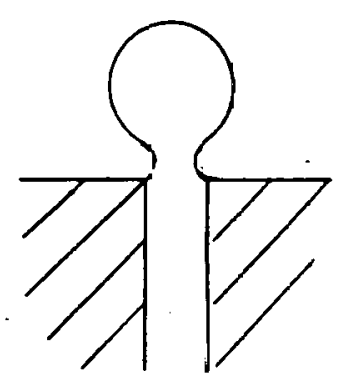

(d)

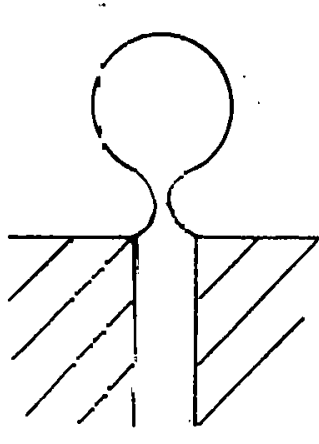

(e)



(f) a

Fig. 3. Steps in bubble growth from a nucleaticn site. 
down of the short, roughly cylindrical region connecting the bubble to the nucleation site. The radius of curvature of this region is much less than that of the bubble (see Fig. 3d). This situation is unstable because the pressure in the bubble is not sufficient to offset the surface tension forces in the small diameter neck of the bubble, and this necked-down region collapses. The resulting implosion produces a characteristic tinkling sound that is readily audible by use of a contact microphone or by placing ones ear against a long metal rod in contact with the boiler shell.

\section{Velocity of Bubble Dilation}

The hniler design envisioned ${ }^{1}, 5$ made use of 0.5 in. ID tubes with a peak design heat flux of about $160,000 \mathrm{Btu} / \mathrm{hr}-\mathrm{ft}^{2}\left(12.04 \mathrm{cal} / \mathrm{sec}-\mathrm{cm}^{2}\right)$. This represents a heat input rate to the liquid column in the boiler tube of $38.4 \mathrm{cal} / \mathrm{sec}-\mathrm{cm}^{3}$, which corresponds to a vapor volume generation rate of approximately $20 \mathrm{~cm}^{3} / \mathrm{sec}-\mathrm{cm}^{3}$ of fluid at around $800^{\circ} \mathrm{C}\left(1500^{\circ} \mathrm{F}\right.$ )

In relating this to the velocity of the liquid-vapor interfaces for a set of expanding bubbles, the rate of change in bubble volume per unit of time $d V / d t$ was related to the bubble radius a and the radial velocity of the bubble surface da/dt by

$$
\text { Rate of increase in volume }=\frac{d V}{d t}=4 \pi a^{2} \frac{d a}{d t}
$$

The volume fraction of bubbles in the fluid for $\mathbb{N}$ bubbles per cubic centimeter and a in centimeters is given by

$$
\text { Bubble volume fraction }=\frac{N 4 \pi a^{3}}{3}
$$

From these relations the chart of Fig. 4 was prepared to show the rate of increase in volume as a function of bubble radius, a relationship that is extremely useful in consideration of magnetohydrodynamic effects. The chart is based on the assumption that the bubbles would be expanding at a radial velocity of $0.1 \mathrm{~m} / \mathrm{sec}$. Early work on this problem by Wichner and Hoffman" suggests a maximum or asymptotic bubble growth rate of 0.7 to $0.8 \mathrm{~m} / \mathrm{sec}$ for 




Tig. 4. Effecls of bubble radius and number of bubbles per cubic eentimeter on the vapor volume generation rate for a bubble dilation rate of $0.1 \mathrm{~m} / \mathrm{sec}$. 
bubble sizes above $0.1 \mathrm{~cm}$ (see Fig. 9, p. 27 of Ref. 7). Note that the volume fraction of bubbles at a given vapor generation rate is independent of the assumed bubble radius. Inasmuch as the bubble radial expansion velocity is directly proportional to the vapor generation rate, the chart of Fig. 4 can be used readily to obtain vapor generation rates for other radial velocities of the vapor-liquid interface of the bubbles simply by multiplying the vapor generation rate by the bubble dilation velocity in meters per second and by a factor of 10 .

\section{MHD Effects on Nucleation}

The magnetohydrodynamic pressure force acting to resist the initial stage of bubble growth (see Fig. 3a) can be estimated very roughly by considering the slug of liquid pushed across the magnetic field ahead of the free surface. Actually, of course, the displacement velocity of elemental volumes of liquid in front of the advancing bubble would be inversely proportional to the square of the radial distance from the center of the bubble, but a fair approximation is given by simply considering a cylindrical slug having the same radius as the bubble and a length in the direction of motion equal to the bubble radius. In making the calculations it is convenient to assume that the axis of the bubble and nucleation site and hence the direction of motion is normal to the lines of magnetic flux. An analysis was made initially by considering the cylindrical slug as a fluid element contained in a pipe having a wall whose electrical conductivity was the same as that of the fluid. The magnetohydrodynamic relations given in Ref. 8 were then used to estimate the pressure required to produce bubble growth. The steps required in the derivation made following this approach proved to be a bit involved and not easy to follow. In reviewing a draft of this

report F. J. Young suggested a simpler and more fundamental approach, and this was adopted in place of that used initially.

As a first approximation it can be assumed that the only resistance to the flow of the current induced by the movement of the conductirig slug through the magnetic field is the resistance within the slug itself. (This will somewhat overestimate the current and hence the force required 
to move the slug.) On this basis the current density induced in the slug is then simply

$$
J=\sigma U \mathrm{UB}
$$

- Where $J$ is the induced current density, $\sigma$ is the electrical conductivity of the fluid, $U$ is the velocity, and $B$ is the magnetic field strength. The electromagnetic body force acting on the slug is then given hy

$$
\text { Furce. }=\text { ALJB }
$$

where $A$ is the cross-sectional area of the slug in a plane normal to the direction of motion and $L$ is the length of the slug. Substituting the value for $J$ given by the first equation in the second gives:

$$
\text { Force }=A L \sigma \mathrm{UB}^{2}
$$

The pressure differential $\triangle P$ between the vapor in the bubblc and the surrounding liquid required to overcome the magnetohydrodynamic force is given by:

$$
\Delta \mathrm{P} \cdot=\frac{\text { Force }}{\mathrm{A}}=\mathrm{I \sigma U \textrm {B } ^ { \mathrm { B } }}
$$

For the case at hand, $L=0.0001 \mathrm{~m}, \sigma=5 \times 1.0^{6} \mathrm{mho} \cdot \mathrm{m}^{-1}, \mathrm{U}-0.1 \mathrm{~m} / \mathrm{scc}$, and $B=4 \cdot \operatorname{Tesla}(40 \mathrm{kG})$, and hence

$$
\begin{aligned}
\Delta P=0.000 \perp \times 5 \cdot \times 10^{6} \times 0.1 \times: 16 & =800 \mathrm{~N} \cdot \mathrm{m}^{-2} \\
& =0.116 \mathrm{psi}
\end{aligned}
$$

This value agrees well with that from the initial analysis which was 524 $\mathrm{N} \cdot \mathrm{m}^{-1}(0 . \odot 76 \mathrm{psi})$. The dit'terence stems from the fact that the initial analysis assumed a wall conductance equal to the fluid slug conductance, and thus underestimated the current flow. whereas the approach used here overestimates. This difference is not significant because either idealized model gives only a rough approximation to the actual case. 
The vapor pressure in a bubble. in equilibrium must exceed the pressure in the liquid to overcome the surface tension. The latter can be considered as if it were. a thin shell in tension, and the pressure can be related to the surface tension and bubble radius by:

$$
\Delta P=\frac{2 \times(\text { Surface Tension })}{a}
$$

A surface tension of 70 dynes/ $\mathrm{cm}$ for a $0.01 \mathrm{~cm}$ radius bubble entails a pressure differential of 14,000 dynes $/ \mathrm{cm}^{2}$ for pressure equilibrium across a spherical bubble surface. Thus the magnetohydrodynamic force restraining the expansion of the bubble in this case is less than $1 \%$ of the surface tension force. If the radial velocity of the bubble surface were to be $1 \mathrm{~m} / \mathrm{sec}$ instead of $0.1 \mathrm{~m} / \mathrm{sec}$, the magnetohydrodynamic pressure force would become 524 dynes $/ \mathrm{cm}^{2}$ which is about $4 \%$ of the surface tension force. Thus, it appears that the magnetohydrodynamic forces acting to restrain the expansion of bubbles in the bubbly flow region in a boiler tube will have little effect on the boiling process.

\section{MHD Effects on Boiling Sounds}

The same sort of analysis carried out above can be used to investigate qualitatively the effects of magnetohydrodynamic forces on bubble implosion. When the bubble formation reaches the stage indicated in Fig. $3 e$, the fluid around the neck of the bubble accelerates inward rapidly. If the motion is transverse tin the magnetic field, magnetohydrodynamic forces will act to restrain the implosion and reduce the velocity at which the opposing free surfaces will impact. Note that if the-axis of the neck of the bubble lies along the lines of magnetic force, the magnetohydrodynamic forces will be symmetrical and the implosion will still occur around a quasi-cylindrical cavity. However, if the axis of the bubble is normal to the direction of the magnetic fieln, the implosion will occur in an asymmetric fashion because the magnetic field will. act to reduce the imploding velocity along one axis but will not do.so along the other, and the shape of the quasicylindrical cavity will become elliptical rather than cylindrical in cross section. Inasmuch as the velocity at impact would be higher than that for 
the expanding bubble, one would expect that there might be some small but not negligible effect on the boiling noise as the magnetic field is increased.

APPARATUS

The experiment was conducted using a single cartridge electric heater (Firerod) in a capsule as shown in Fig. 5. The capsule consisted of a piece of.2-in. stainless steel pipe about $3 \mathrm{ft}$ long with the ends closed by welded pipe raps and a Firerod heater $1 / 2$. in. In diameter ingerted up the center. Nucleation sites ${ }^{\circ}$ were provided on the lower portion of the electrical resistance-heated region of the Firerod by shrinking a set of cylindrical rings over the oD of the Firerod. In addition, a nucleation site in the form of a "hot finger" was added a few inches below the lower end of the heated length of the Firerod. This consisted of a capillary hole drilled into a block which extended perpendicularly out from the side of the 2-in. pipe and included an electric resistance heater on the outboard end for use in generating a local hot spot. The idea was to heat the "hot finger" sufficiently to produce a vapor bubble in the capillary hole and assure a sustained source of small vapor bubbles that would act. like a pilot light to sustain nucleation if it should be inlerrupted a.t the ilucleat1on sites on the:Firerod. To offset the rather large heat losses from the outer surface of the capsule, a set of electric heaters : was wrapped around the outer perimeter of the $2-i n$. pipe. The pipe was filled with liquid potassium to above the top of the Firerod, or about half way up the capsule. Vapor generatien. in the heatod, or boiler, Ieyiul of the capsule rises to the top where it is condensed by forced air cooling and as a consequence of heat losses by thermal radiation and conduction from the wall to the surroundings.

\section{Instrumentation}

Ten thermocouplee were installed on the capsule wall to give an indication of the temperature distribution. One of these was installed in the hot outer end of the hot finger, one.in the condenser portion of the capsule, and the balance were distributed along the heated length. Extensive 


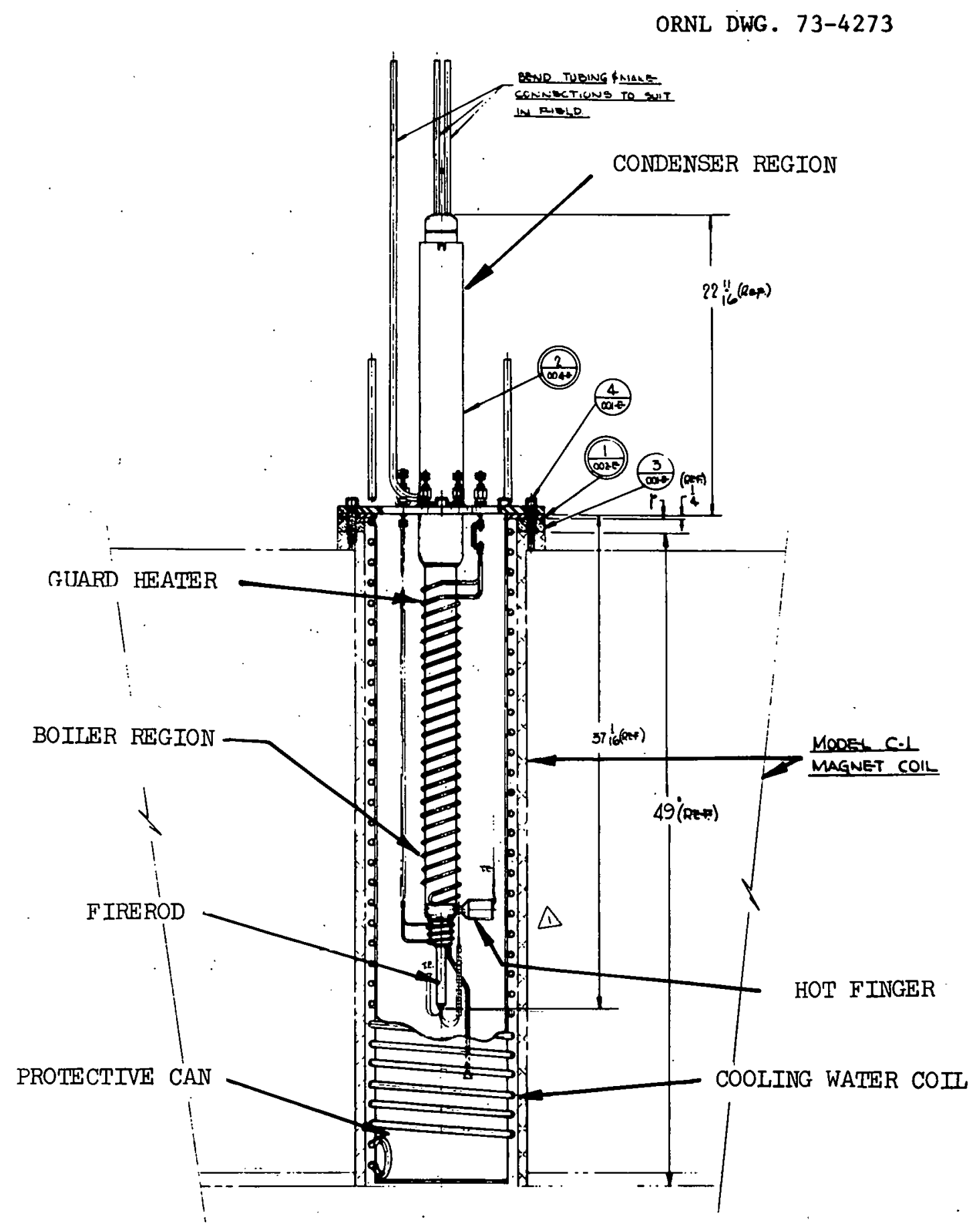

Fig. 5. Section through the installation of the potassium boiler in the magnet. 
experience in the past has indicated that, if nucleate boiling is occurring in a capsule of this type, the temperatures will all be close together except that the hot finger, when being used, must run substantially above the temperatures in the boiler-condenser regions.

It has also been found very helpful in running test,s on potassium boilers to include a microphone or sound pickup rigidly attached to the boiler with a rod sufficiently long to keep the temperature of the pickup to a level close to room temperature. For the experiment on this pickup, it was connected to a sound amplifier and speaker, a tape recorder, and a Sanborn 150 recording oscillograph.

The three heaters were connected to dc power supplies with a voltmeter. and ammeler in each circuit to permit the measurement of the power input to each heater.

The complete potassium builer assembly was mounted inside of a 9 in. diameter and $4 \mathrm{ft}$ long metal can, so that, if a potascium leak were lu develop, the solenoid magnet would be protected. This can in turn was mounted inside a large solenoid magnet having a bore of ll in. and a coil length of 36 in.

\section{TEOT PROCEDURE}

The potassium boiler was evacuated and thoroughly degassed before filling with potassium. It was then operated for some hours at around $1000^{\circ} \mathrm{F}$ so that the potassium would reduce any nxide films on the otainlexs steel surfaces. The potassium charge was then dumped and a fresh charge supplied. This assured thorough degassing and cleaning of the boiler surfaces.

An initial shakedown run was conducted in ortober to assure that all of the instrumentation was working satisfactorily. The results of this test indicated that the magnetic field had little effect on boiling other than to cause some reduction in the amplitude of the boili.ing sounds. Scheduring difficulties, particularly with the MG sets for supplying power to the solenoid magnet, prevented further running until April 5, 1973. The test was begun by heating the boiler up with no magnetic field and checking 
out the instrumentation. Some difficulty was experienced with the sound pickup, but this seemingly was corrected by tightening up a number of loose connections.

The system was warmed up by setting the guard heaters at $1080 \mathrm{~W}$, the hot finger at $186 \mathrm{~W}$, and the Firerod at $730 \mathrm{~W}$. The temperatures increased as indicated in Fig. 6. There was no sign of boiling either from the sound pickup nor was any sound detectable by putting one's ear against a steel rod held against the boiler. This situation continued until the hot finger temperature (Thermocouple No. 8, the highest temperature trace in Fig. 6) had diverged by about $200^{\circ} \mathrm{F}$ from the temperatures indicated by the thermocouples on the boiler. At this point both the Sanborn recorder and direct audible sensing indicated that nucleate boiling had been initiated. Note that the initiation of nucleate boiling led to a rapid evolution of vapor, and this quickly raised the condenser temperature (Thermocouple No. 9, the lowest temperature string of points in Fig. 6) until it reached the boiler temperature. To avoid excessive divergence of the hot finger temperature the electric power to the hot finger was cut back once boiling was initiated. As can be seen in Fig. 6 the initial reduction was too great and resulted in a fairly rapid drop in temperature of the hot finger. Further adjustments were necessary to achieve the desired spread between the hot finger temperature and the boiler temperature. Following these adjustments the power to all three heaters was kept constant and the temperatures were allowed to stabilize. After the temperatures had thoroughly stabilized the magnet was turned on and the strength of the magnetic field was increased in substantial steps with sufficient time allowed between steps to assure good stabilization of the temperatures.

\section{TEST RESULTS}

The data recorded for the power input to the heaters coupled with a summary of the boiler temperatures and observations on the boiling sounds as detected with a steel rod held against the potassium boiler are presented in Table 1. It should be mentioned that because of the large thermal inertia in the system, it took quite a while to stabilize the temperatures in the initial part of the test, but in the latter portion of the test this was not 
ORNL DWG. 74-1230



Fig. 6. Strip chart temperature record of the potassium boiler startup. 
Table 1. Data Taken in the Course of a Test April 5, 1973

on the Effects of a Magnetic Field on the Nucleate Boiling of Potassium

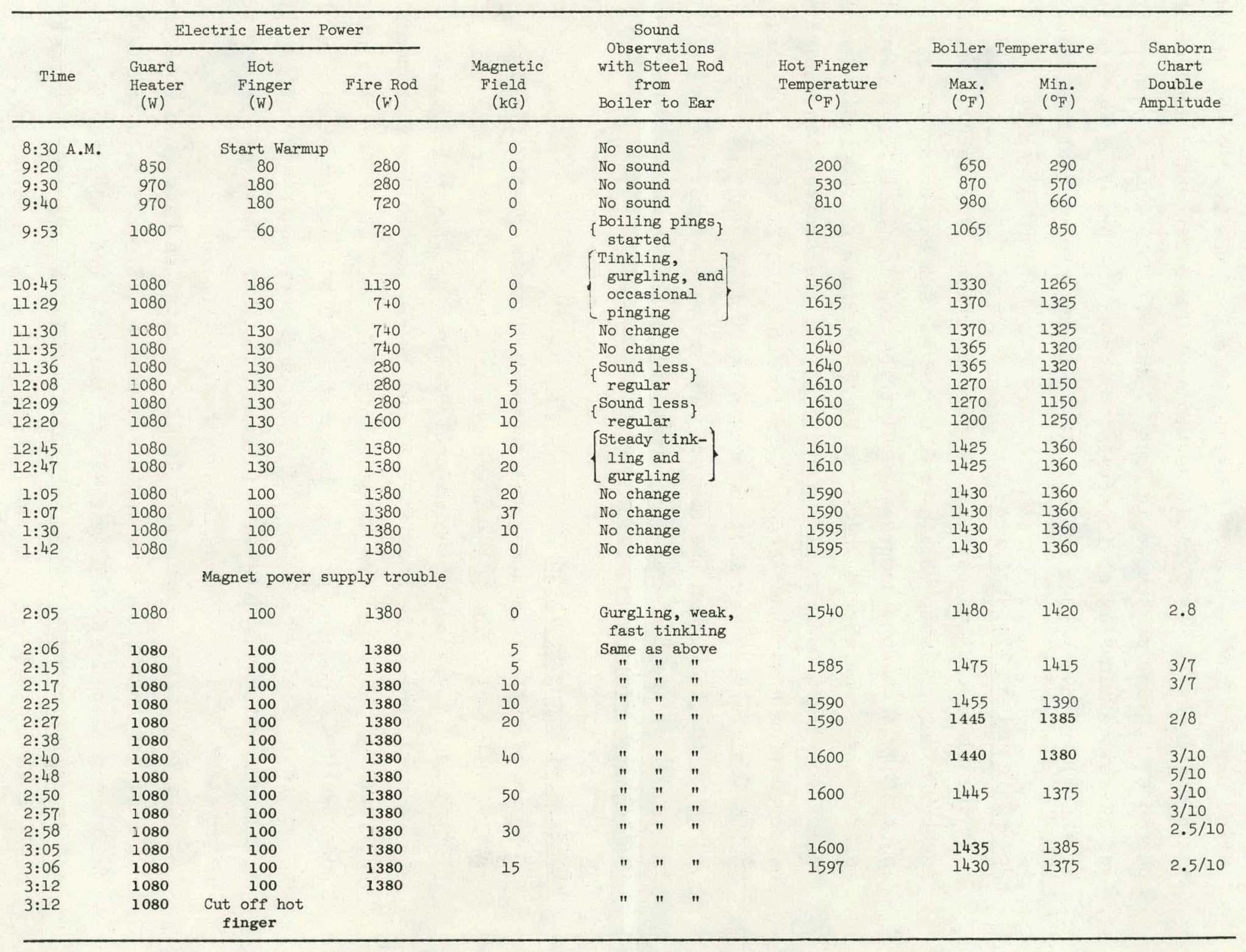


the case. Both the time required for the temperature stabilization in the latter part of the test and the small effect of changes in the magnetic field are indicated by typical sections of the strip chart used in the temperature recorder and shown in Figs. 7 and 8 . Note that the chart speed was increased manually at intervals to sprcad the printout (as in Figs. 6, 7 , and 8) so that values for individual thermocouples could be read easily.

\section{Spread in Boiler Temperatures}

The width of the scatter band for the boiler temperatures in Fig. 6 shows whether nucleato boiling was vecurring and was being effective in maintaining a uniform temperature distribution in the boiler. Note how rapid $\perp y$ tle lemperatures indicated by the various thermocouples on the boiler converged when boiling was initiated; the scatter band quickly narrowed from a width of about $200^{\circ} \mathrm{F}$ to about $100^{\circ} \mathrm{F}$. Although small changes in the temperature distribution within the boiler sometimes occurred in the course of the test when the magnetic field was changed, the overall spread in the boiler temperatures was substantially independent of the strength of the magnetic field.

\section{Effects of Magnetic Field}

The effects of changing the strcngth of the magnetic field are shown in Fig. 9 in which the highest and lowcst temperalures in the boiler are plotted as a function of the magnetic field. The power input to the Firerod was reduced during the runs at $5 \mathrm{kG}$ and $10 \mathrm{kG}$, and this was responsiblc for the lower temperatures for those points. A small arrow has been placed underneath the points for each magnetic field strength to indicate whcthcr the magnetic field was being increased or decreased in approaching the condition for whicli lie duta were taken. Note that the spread in the boiler temperatures did not change much with magnetic field.

The hot finger temperature is also plotted in Fig. 9 to show the effects of the magnetic field on this quantity. It must be noted that the thermocouple in the hot finger was at the outboard end under the heater and hence indicated a temperature much above that at the boiler wall where boiling took place from the nucleation site of the hot finger. It is believed that changes in the differences in the liquid flow distribution 
ORNL DWG. 74-1231

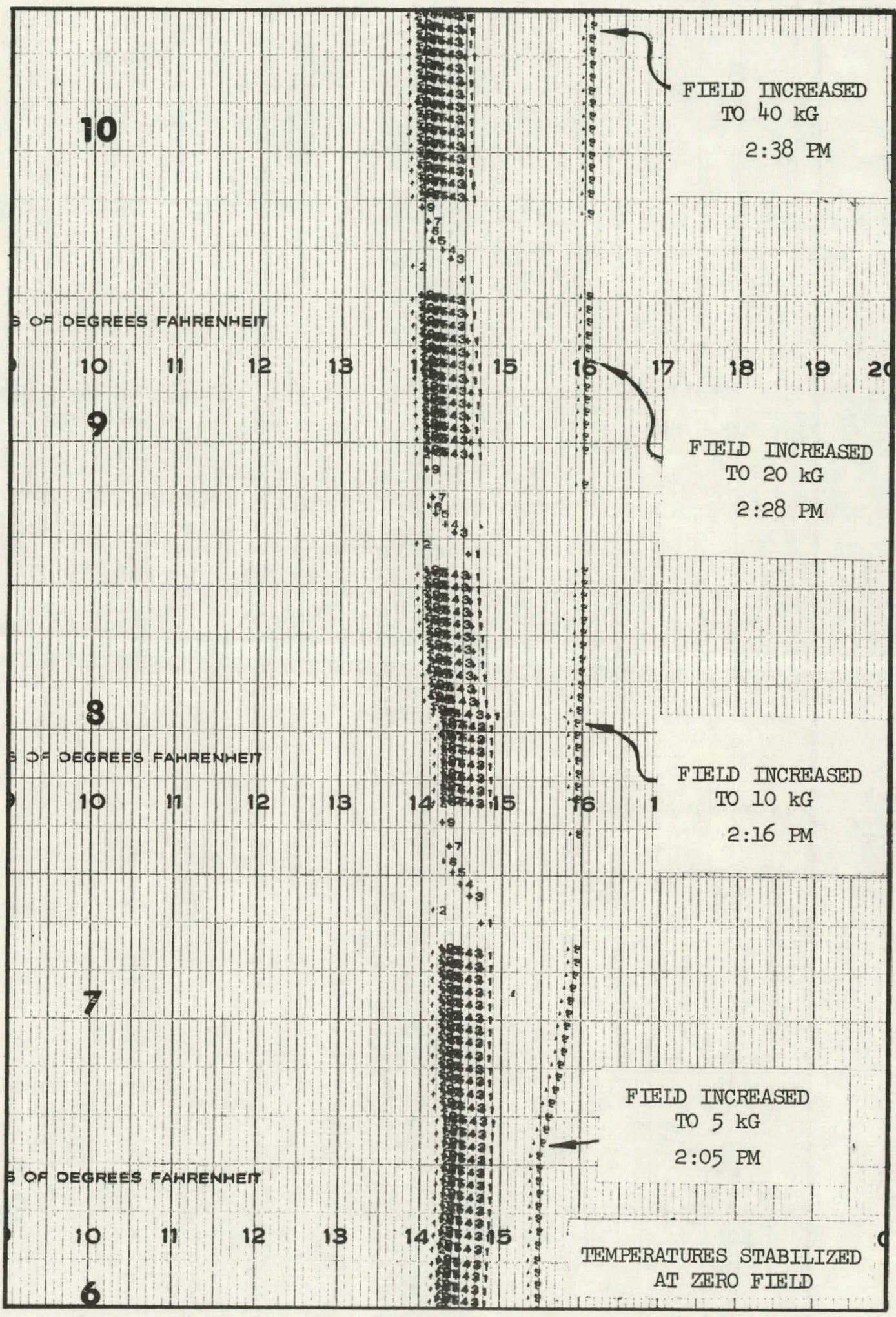

Fig. 7. Strip chart temperature record for operation from 0 to $40 \mathrm{kG}$. 
ORNL DWG. 74-1232

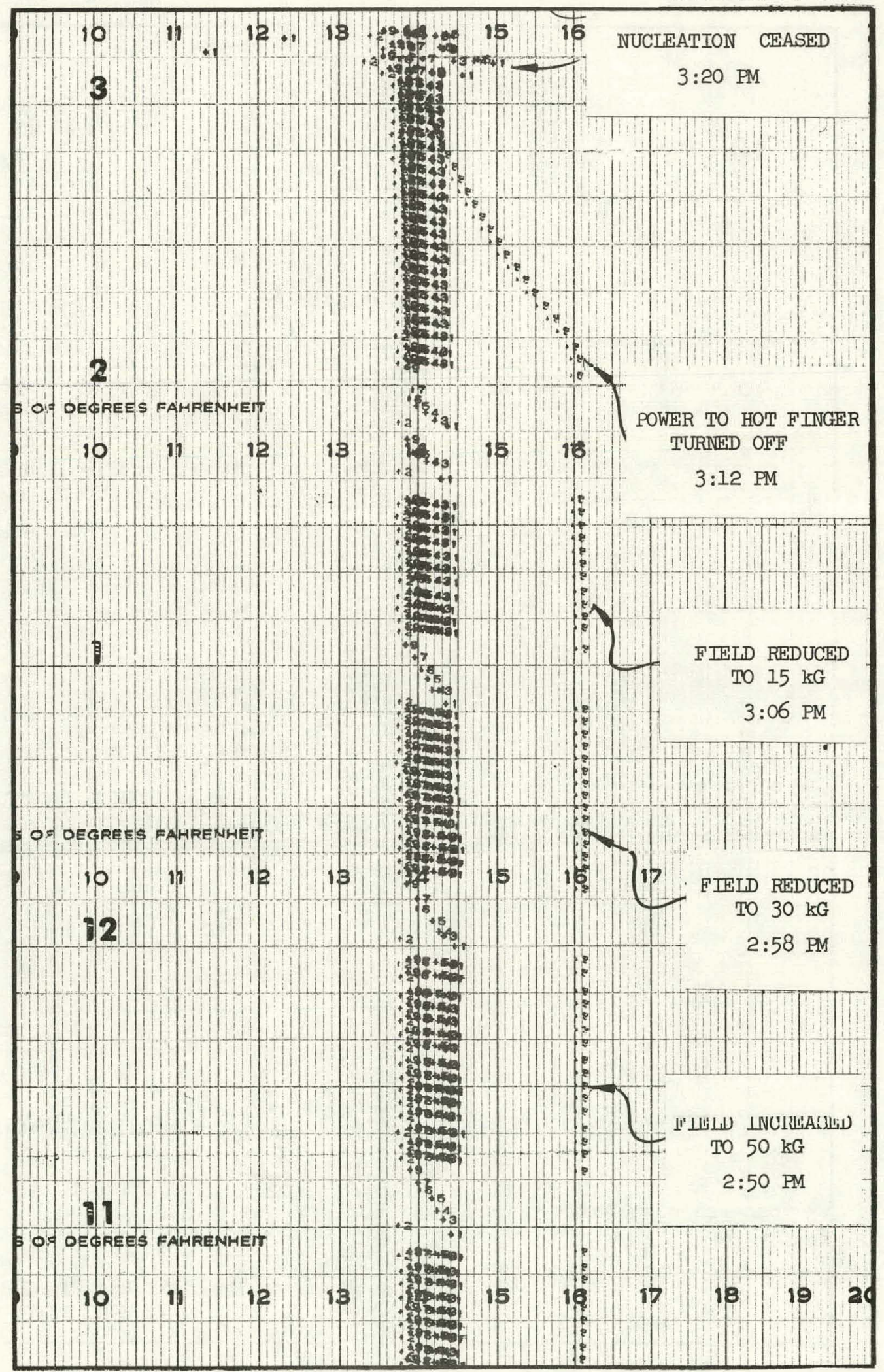

Fig. 8. Strip chart temperature record for operation from 40 to $50 \mathrm{kG}$ and back down to $14 \mathrm{kG}$ followed by cutting off the power supply to the hot finger. 




Fig. 9. Upper and lower limits of the scatter band for the potassium boiler temperature and the hot finger temperature plotted as a function of the magnetic field. The arrows beneath the poinls for the minimum boiler temperature indicate the direction in which the magnetic field was changed in approaching the point. 
within the boiler as a consequence of magnetohydrodynamic effects on thermal convection currents in the liquid potassium rather than as a consequence of effects on nucleate boiling. The changes in the temperature distribution along the boiler wall with changes in the field are believed to have stemmed from similar effects.

Direct audible observations of the boiling sounds using a steel rod between the red hot capsule and the writer's ear showed no appreciable effect of the magnetic field on the tinkling and gurgling sounds normally associated with boiling potassium in a boiler of this type. However, there was a marked reduction in the occasional loud pinging sounds, and this is believed to have come about as a consequence of the magnetohydrodynamic effects which would act to reduce the rate at which large bubbles could implode.

\section{Sanborn Recorder Charts}

The Sanborn recorder was used throughout the test to record the sound signal from a rather insensitive pickup unit attached to a metal extension rod on the capsule. During the bulk of the test the sanborn recorder was operated at a low chart speed but at regular intervals the chart speed was increased by a factor of 100 for a few seconds to give hetter definition of the signal. These traces are presented in Figs. 10 to 13 for each lcvel of magnetic field strength.

The most pronounced characteristic of the signal is a heavy $60 \mathrm{~Hz}$ hum caused by the high level of amplification being used. Sunerimposed on this hum is an occasional noise spike, most pronounced in the recordings taken at low chart speed but occasionally appearing during the short interval of high chart speed (see Fig. 11). These noise spikes are associated with randowi buble cullapse phenomenon superimposed on a regular boiling pattern which produced insufficient noise to substantially affect the recorder tracing. The magnetic field strength appeared to have little effect on the amplitude of these noise spikes but the tracing taken at 50 kilogauss field strcngth (Tig. 12) had a noticeabıy higher frequency of events.

It is most unfortunate that the sound pickup was functioning so poorly that Figs. 10 through 13 are not very meaningful; far higher signal-to-noise 
TIME
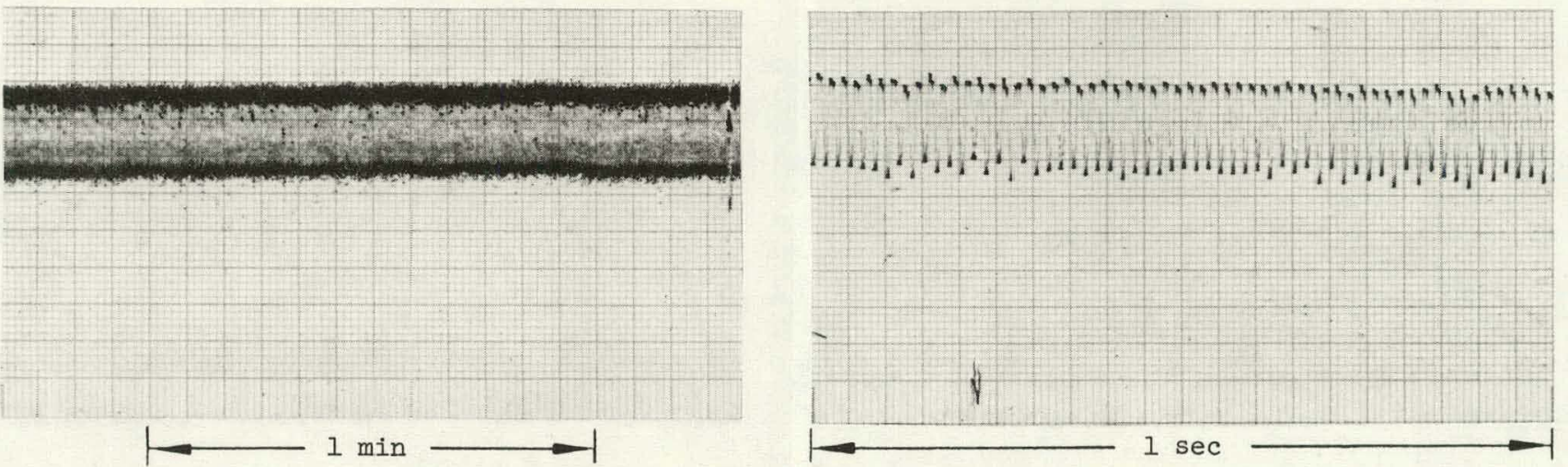

MAGNETIC FIELD $=0 \mathrm{KG}$
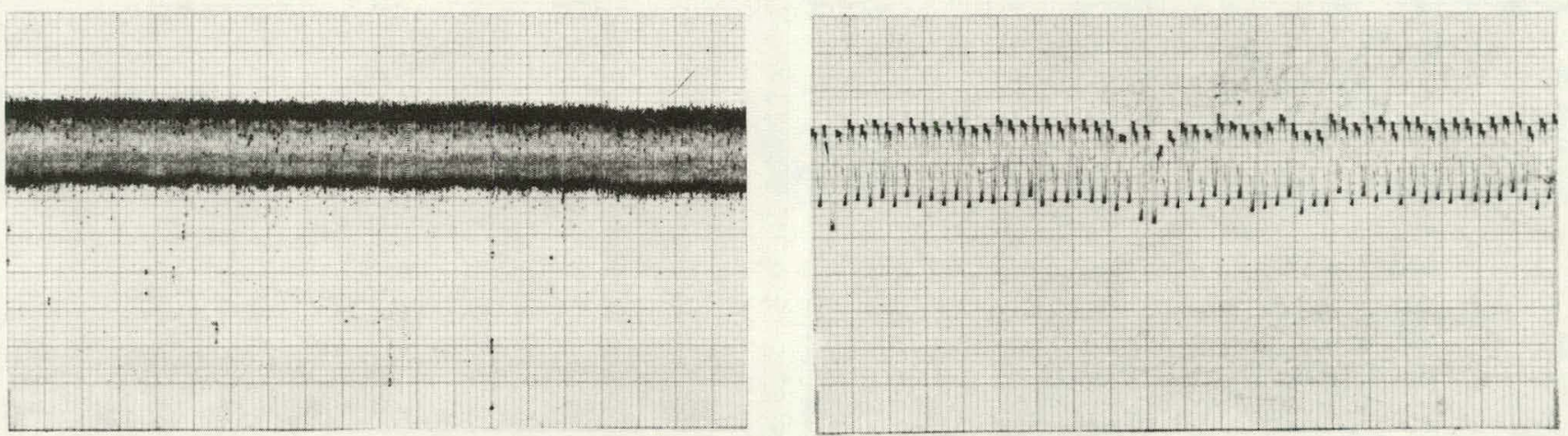

MAGNETIC FIELD $=5 \mathrm{KG}$

Iig. 10. Oscillograph traces from the sound pickup on the potassium boiler. 

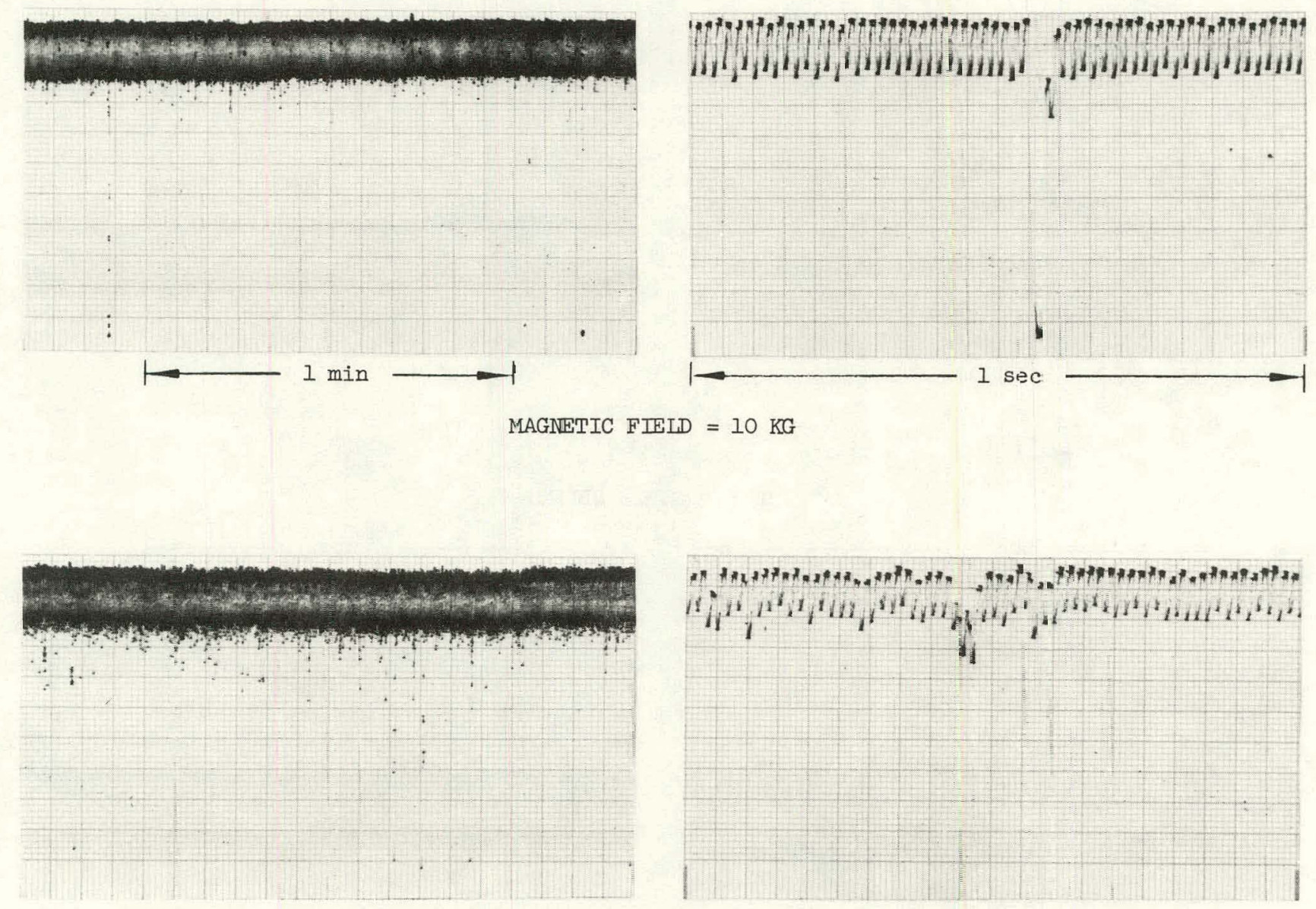

MAGNETIC FIELD $=20 \mathrm{KG}$

Fig. 1I. Oscillograph traces from the sound pickup on the pctassium boiler. 



MAGNETIC FIELD $=40 \mathrm{KG}$


MAGNETIC FIELD $=50 \mathrm{KG}$

Fig. 12. Oscillograph traces from the sound pickup on the potassium boiler. 

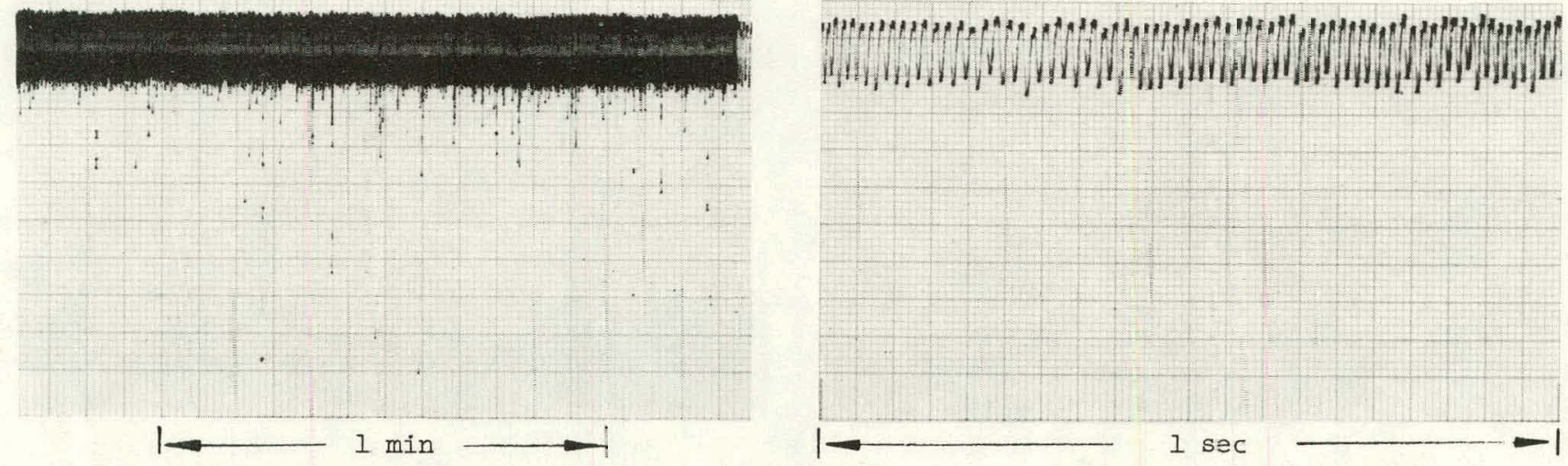

MAGNETIC FIED D $30 \mathrm{KG}$
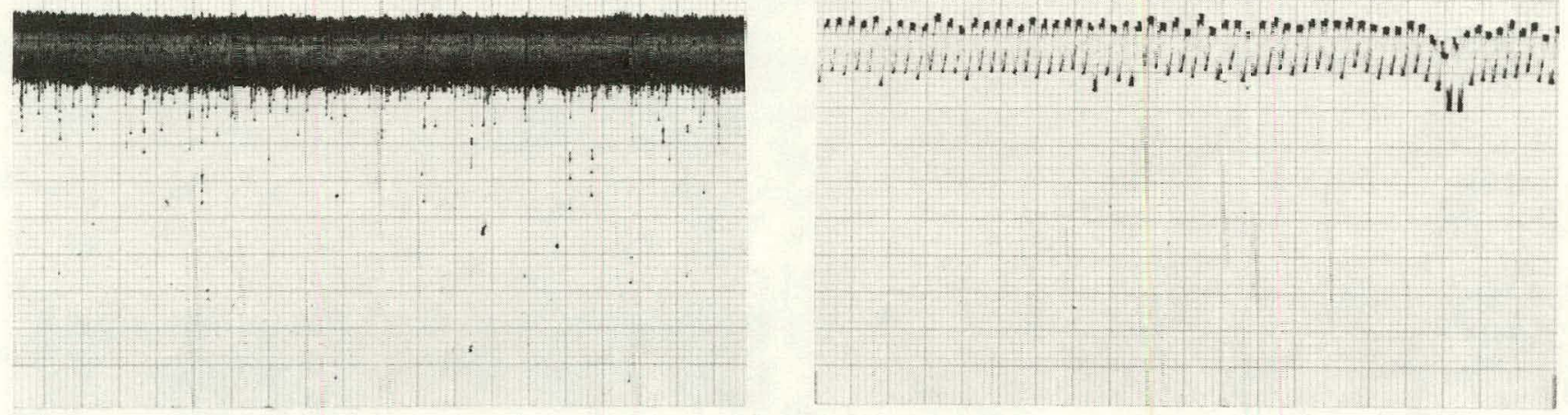

MAGIETIC FIEID $=75 \mathrm{KG}$

Fig. 13. Oscillograph traces from the sound pickup on tre pctassium boiler. 
ratios have normally been obtained, in previous work with boiling potassium and the traces have been" much more meaningful.

Termination of the Test

The last step in the test was to reduce the field to $15 \mathrm{kG}$, allow conditions to stabilize (which occurred within a few minutes), and then turn off the hot finger to determine whether nucleation had been occurring from the hot finger with the strong magnetic field. After a few minutes the hot finger temperature dropped from $160^{\circ} \mathrm{F}$ above the mean temperature for the boiler to the boiler temperature at which point nucleation abruptly ceased. This was evident from the cessation of the audible. sounds, the reduced amplitude of the Sanborn oscillograph traces, and the fairly rapid divergence in the temperatures on the recorder evident at the top of Fig. 8. Thus, it became clear that the hot finger was contributing to nucleation throughout the test and, as had been found during extensive test work under the Space Power Plant program, the single Firerod potassium boiler unit did not function smoothly at low Firerod power outputs (around. $\mathrm{kW}$ ) unless an auxiliary nucleation site in the form of a hot finger was provided.

\section{CONCLUSTIONS}

Both the analyses and the experiments indicate that a strong magnetic field has little effect on nucleate boiling of potassium, and hence this consideration should not present a problem for designs employing a potassium boiler mounted directly: in the blanket of' a f'ull-scale thermonuclear power plant. 


\section{REFERENCES}

1. A. P. Fraas, Conceptual Design of the Blanket and Shield Region and Related Systems for a.Full Scale Toroidal Fusion Reactor, USAEC Report ORNL-TM-3096, Oak Ridge National Laboratory, May 1973.

2. A. P. Fraas, Problems in Coupling a Gas Turbine to a Thermonuclear Reactor, ASME Paper No. 72-GT-98, December 1971.

3. A. P. Fraas, Analysis of a Recirculating Lithium Blanket Designed to Give a Low Magnetohydrodynami.c Pumping Power Requirement, USAEC

Report ORNL-TM-3756, Oak Ridge National Laboratory, September 1972.

4. 5. J. Leverettc, $\Lambda$ n Inveatigation of lie Temperature Uistrubution in the 'Lithium Blanket of a Fusion Reactor, USAEC Report ORNL-TM-3701, May 1,97?.

5. T. T.Robin, Design of Boiler-Superheater Units for Representative Cesium and Potassium Space Power Plants, USAEC Report ORNL-TM-2080, Oak Ridge National Laboratory, September 1968.

6. J. A. Edwards and H. W. Hoffman, Superheat with Boiling Alkali Metals, Proceedings of Conference on Application of High-Tcmperature Instrumentation to Liquid Metal Experiments, USAEC Report ANL-7100, Argonne National Laboratory, December 1965.

7. R. P. Wichner and H. W. Hoffman, Vapor Bubble Growth Rates in Superheated Liquid Metals, USAEC Report ORNL-TM-1413, Oak Ridge National Laboratory, July 1966.

8. M. A. Hoffman and G. A. Carlson, Calculation Techniques for. Estimating the Pressure Losses for Conducting Fluid Flows in Magnetic Fields, UCRL-51010, Lawrence. Radiation Laboratory, Livermore, February.4, 1971.

9. R. E. MacPherson, Techniques for Stabilizing Liquid Metal Pool Boiling, II-B/II, Conference Internationale Sur La Surete dés Reacteurs A Neutrons Rapides, September 22, 1967. 
OAK RIDGE NATIONAL LABORATORY

OPERATED BY

UNION CARBIDE CORPORATION

NUCLEAR DIVISION

CANGONE

POST OFFICE BOX $X$

OAK RIDGE, TENNESSEE 37830

\section{SPECIAL 4TH CLASS RATE BOOKS} return it to the above address. 